\title{
POSITIVE SELF-ESTEEM, SATISFACTION AND THE UNPLUGGED PROGRAM AMONG SLOVAK SCHOOLCHILDREN
}

\author{
Olga Orosová, Maria Bacikova-Sleskova, \& Beata Gajdosova \\ Department of Educational Psychology and Health Psychology, Faculty of Arts, \\ Pavol Jozef Šafárik University in Košice (Slovakia)
}

\begin{abstract}
Background: The aims of this study were to explore the changes in schoolchildren's positive self-esteem, satisfaction with themselves and their surroundings following the Unplugged program as well as the indirect effect of Unplugged on satisfaction through self-esteem. Method: In the school year 2013/2014, the program Unplugged was implemented in Slovak primary schools. The study was carried out as a cluster randomized controlled trial with data collection conducted immediately before program implementation (T1), immediately after program implementation (T2), and at three months (T3) after program implementation. The program included 1195 participating schoolchildren $(\mathrm{M}=11.52 ; 47.4 \%$ boys). The schools were randomly assigned to an experimental $(n=540)$ and control group $(n=655)$. The experimental group was exposed to the program Unplugged which consisted of 12 lessons (http://www.eudap.net/). The effect of participating in Unplugged and gender was explored through the changes in positive self-esteem and satisfaction with themselves and surroundings. This was followed across the three contact points at the baseline (T1) and two follow-up measures (T2, T3) with group (experimental/control) and gender as the between-subject factors. GLM Repeated Measures were used for the data analyses. The indirect effects of the group (experimental/control) on satisfaction through self-esteem were explored using the Hayes' PROCESS tool. In order to explore whether the indirect effect was moderated by gender, separate analyses were performed on each respective part of the data. Results: There was a significant main effect of time measures on the self-esteem expressed by the schoolchildren. The contrast analysis revealed that positive self-esteem was significantly higher at the second follow-up (T3) than at the first follow-up test (T2). There was a significant interaction effect between self-esteem and the group. This effect indicated that the level of self-esteem differed between the participants and non-participants of the Unplugged program. The contrast analysis revealed that positive self-esteem was significantly higher at the second follow-up (T3) than at the baseline test (T1) among the participants of the Unplugged program. The partial indirect effects of the group (experimental/control) on satisfaction through self-esteem was found at the second follow-up test (T3) among girls. Conclusion: The results have confirmed a short-term effect of the Unplugged program in increasing the positive self-esteem of schoolchildren, as well as an indirect effect of satisfaction in girls through positive self-esteem three months after program implementation.
\end{abstract}

Keywords: Unplugged program, self-esteem, satisfaction, schoolchildren.

\section{Introduction}

Self-esteem, satisfaction with life, satisfaction with themselves and well-being have created important personal components of health-related interventions. It has been found that interventions increasing self-esteem, life satisfaction and optimistic life orientation with the aim of reducing bullying among classmates were likely to not only benefit those who were victimized, but all students (Låftman \& Modin, 2017; Blood et al., 2011). Self-esteem development may be the target of interventions aiming to improve quality of life in addition to treating adolescents' psychopathology (Jozefiak et al., 2017). Moreover, well-being, self-control, and self-esteem have been identified as important factors in preventing problematic internet use (Mei, Yau, Chai et al., 2016).

Self-esteem mediates the association between quality of life and suicidal ideation (Fulginiti, \& Brekke, 2015) as well as between the perception of one's body image and psychological distress (Duchesne, Dion, Lalande et al., 2017). There was also a mediation effect of self-esteem found on well-being and social anxiety (Fernandes, 2018). Self-esteem has also been identified as an important component in the prevention of eating problems in adolescents (Barker\& Bornstein, 2010; Tirlea et al., 2016). 
Gender differences and personal characteristics have been found to be important factors in the effectiveness of school-based drug use prevention programs; factors that could cast light on the psychological mechanism of the program effect (Vigna-Taglianti et al., 2009). Research has confirmed that school-based prevention programs, which target multiple risk behaviours and help build self-esteem and life skills, are more likely to be effective in preventing drug use (Warren, 2016). However, there have been inconsistent results about the drug use prevention program effects among boys and girls (Vigna-Taglianti et al., 2009).

This study aimed to explore the effectiveness of the school-based curriculum „Unplugged“ among Slovak schoolchildren. This program to prevent substance use is based on the social influence approach and addresses social and personal skills, knowledge, and normative beliefs (Vigna-Taglianti et al., 2014). The data-based drug use prevention programs have been seldom accessible at Slovak elementary schools. Schoolchildren's positive self-esteem, satisfaction with themselves and with their surroundings and the moderation effect of gender were the indicators chosen in this study for examining the effectiveness of the Unplugged program.

\section{Objectives}

The objectives of this study were to explore the changes in schoolchildren's positive self-esteem, satisfaction with themselves and with their surroundings following the Unplugged program as well as the indirect effect of Unplugged on satisfaction through self-esteem.

\section{Methods}

\subsection{Sample and study design}

In the school year 2013/2014, the program Unplugged was implemented in Slovak primary schools. The study was carried out as a cluster randomized controlled trial with data collection conducted immediately before program implementation (T1), immediately after program implementation (T2) and at three months (T3) after program implementation. The program included 1195 participating schoolchildren ( $\mathrm{M}=11.52 ; 47.4 \%$ boys). The schools were randomly assigned to an experimental $(\mathrm{n}=540)$ and control group $(n=655)$. The experimental group was exposed to the program Unplugged which consisted of 12 lessons (http://www.eudap.net/). The effect of participating in Unplugged and gender was explored through the changes in positive self-esteem and satisfaction with themselves and surroundings. This was followed across the three contact points at the baseline (T1) and two follow-up measures (T2, T3) with group (experimental/control) and gender as the between-subject factors.

\subsection{Method}

The measures included in the present study were:

Self-Liking and Self-Competence Scale (SLCS-R)

Self-esteem was measured using the 16-item self-liking and competence scale-revised (SLCS-R) (Tafarodi\& Swann, 2001). Based on Principal Component analysis, a 7-item component of positive self-esteem (Crombach $\alpha=0.793$ ) was used (Berinsterova, 2015). The items were assessed on a 5-point Likert scale ( 1 - totally disagree, 5 - totally agree), where higher scores indicated a higher level of positive self-esteem.

Satisfaction with themselves and surroundings (ESPAD 2011)

Satisfaction was measured by three questions: "How satisfied are you usually with the family's economic situation? How satisfied are you usually with your health? How satisfied are you usually with yourself?" The responses ranged from not at all satisfied (1) to very satisfied (5), where higher scores indicated more satisfying/positive relationships with themselves and their surrounding (Cronbach alpha=0.765).

\subsection{Statistical analyses}

GLM Repeated Measures were used for the data analyses. The indirect effects of the group (experimental/control) on satisfaction through self-esteem were explored using the Hayes' PROCESS tool (with satisfaction at the baseline measure as the covariate variable). In order to explore whether the indirect effect was moderated by gender, separate analyses were performed on each respective part of the data.

\section{Results}

There was a significant main effect of time measures on the self-esteem expressed by schoolchildren (Table 1,2). The contrast analysis (Table 3) revealed that positive self-esteem was significantly higher at the second follow-up (T3) than at the first follow-up test (T2). 
There was a significant interaction effect between self-esteem and the group (Table 2). This effect indicated that the level of self-esteem differed between the participants and non-participants of the Unplugged program. The contrast analysis revealed that positive self-esteem was significantly higher at the second follow-up (T3) than at the baseline test (T1) among the participants of the Unplugged program (Figure 1).

Table 1. Descriptive characteristics of the sample.

\begin{tabular}{|c|c|c|c|c|c|c|c|c|c|c|c|c|c|}
\hline & & \multicolumn{2}{|c|}{$\mathrm{S}^{\mathrm{T} 1}$} & \multicolumn{2}{|c|}{$\mathrm{SE}^{\mathrm{T} 1}$} & \multicolumn{2}{|c|}{$\mathrm{S}^{\mathrm{T} 2}$} & \multicolumn{2}{|c|}{$\mathrm{SE}^{\mathrm{T} 2}$} & \multicolumn{2}{|c|}{$\mathrm{S}^{\mathrm{T} 3}$} & \multicolumn{2}{|c|}{$\mathrm{SE}^{\mathrm{T3}}$} \\
\hline Group & Gender & Mean & SD & Mean & SD & Mean & SD & Mean & SD & Mean & $\mathrm{SD}$ & Mean & $\mathrm{SD}$ \\
\hline \multirow{3}{*}{ CG } & Boys & 12.78 & 2.61 & 26.90 & 6.56 & 12.64 & 2.78 & 23.79 & 8.35 & 12.58 & 2.41 & 25.56 & 6.79 \\
\hline & Girls & 12.93 & 2.14 & 27.45 & 5.36 & 12.63 & 2.28 & 27.27 & 6.38 & 12.57 & 2.51 & 27.02 & 6.15 \\
\hline & Total & 12.87 & 2.35 & 27.22 & 5.89 & 12.64 & 2.50 & 25.79 & 7.47 & 12.58 & 2.46 & 26.40 & 6.46 \\
\hline \multirow{3}{*}{ EG } & Boys & 12.73 & 2.00 & 27.34 & 5.96 & 12.66 & 2.09 & 27.07 & 5.60 & 12.31 & 2.24 & 27.48 & 5.22 \\
\hline & Girls & 12.71 & 2.44 & 27.57 & 5.20 & 12.67 & 2.35 & 27.43 & 5.86 & 12.83 & 1.93 & 28.67 & 6.42 \\
\hline & Total & 12.72 & 2.26 & 27.48 & 5.49 & 12.67 & 2.24 & 27.29 & 5.74 & 12.60 & 2.08 & 28.21 & 6.00 \\
\hline \multirow{3}{*}{ Total } & Boys & 12.76 & 2.35 & 27.09 & 6.30 & 12.65 & 2.49 & 25.17 & 7.48 & 12.46 & 2.34 & 26.37 & 6.24 \\
\hline & Girls & 12.84 & 2.28 & 27.50 & 5.28 & 12.65 & 2.31 & 27.35 & 6.13 & 12.68 & 2.28 & 27.78 & 6.31 \\
\hline & Total & 12.80 & 2.31 & 27.33 & 5.72 & 12.65 & 2.39 & 26.45 & 6.80 & 12.59 & 2.30 & 27.20 & 6.31 \\
\hline
\end{tabular}

Notes: $\mathrm{CG}=$ control group, $\mathrm{EG}=$ experimental group (the Unplugged program), $\mathrm{T} 1$ = baseline measure, $\mathrm{T} 2=$ the first follow-up measure immediately after program implementation, $\mathrm{T} 3=$ the second follow-up measure three months after program implementation, $\mathrm{S}=$ Satisfaction with themselves and surroundings, $\mathrm{SE}=$ Positive self-esteem

Table 2. The repeated-measures effects of time on the Positive Self-esteem and the Satisfaction with themselves and surroundings.

\begin{tabular}{|l|c|c|l|c|c|}
\hline Positive self-esteem (SE) & F & p-value & $\begin{array}{l}\text { Satisfaction with themselves } \\
\text { and surroundings (S) }\end{array}$ & F & p-value \\
\hline SE & 4.27 & 0.014 & S & 2.36 & 0.095 \\
\hline SE x Group & 3.09 & 0.046 & S x Group & 0.35 & 0.708 \\
\hline SE x Gender & 2.57 & 0.077 & S x Gender & 0.84 & 0.434 \\
\hline SE x Group x Gender & 2.83 & 0.060 & S x Group x Gender & 1.55 & 0.213 \\
\hline
\end{tabular}

Table 3. The time contrasts of the Positive Self-esteem and the Satisfaction with themselves and surroundings.

\begin{tabular}{|c|c|c|c|c|c|c|c|}
\hline Positive self-esteem (SE) & SE & $\mathrm{F}$ & p-value & $\begin{array}{l}\text { Satisfaction with } \\
\text { themselves and } \\
\text { surroundings }(S)\end{array}$ & $S$ & $\mathrm{~F}$ & p-value \\
\hline \multirow{2}{*}{ SE } & $\mathrm{T} 1$ vs $\mathrm{T} 2$ & 0.51 & 0.697 & \multirow{2}{*}{ 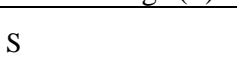 } & T1 vs T2 & 4.29 & 0.039 \\
\hline & $\mathrm{T} 2$ vs $\mathrm{T} 3$ & 5.08 & 0.025 & & $\mathrm{~T} 2$ vs $\mathrm{T} 3$ & 0.68 & 0.412 \\
\hline \multirow{2}{*}{ SE x Group } & T1 vs T2 & 5.02 & 0.026 & \multirow{2}{*}{ S x Group } & T1 vs T2 & 0.37 & 0.544 \\
\hline & T2 vs T3 & 0.01 & 0.930 & & T2 vs T3 & 0.03 & 0.871 \\
\hline \multirow{2}{*}{ SE x Gender } & T1 vs T2 & 1.96 & 0.162 & \multirow{2}{*}{ S x Gender } & T1 vs T2 & 0.80 & 0.372 \\
\hline & T2 vs T3 & 0.73 & 0.394 & & T2 vs T3 & 1.68 & 0.195 \\
\hline \multirow{2}{*}{ SE x Group x Gender } & T1 vs T2 & 0.01 & 0.966 & \multirow{2}{*}{ S x Group x Gender } & T1 vs T2 & 2.73 & 0.099 \\
\hline & $\mathrm{T} 2$ vs $\mathrm{T} 3$ & 4.10 & 0.043 & & $\mathrm{~T} 2$ vs $\mathrm{T} 3$ & 1.60 & 0.206 \\
\hline
\end{tabular}

The partial indirect effects of the group (experimental/control) on satisfaction with themselves and surroundings through positive self-esteem was found at the second follow-up test (T3), three months after the Unplugged program implementation only among girls (Figure 2).

Figure 1. Positive self-esteem x group interaction.

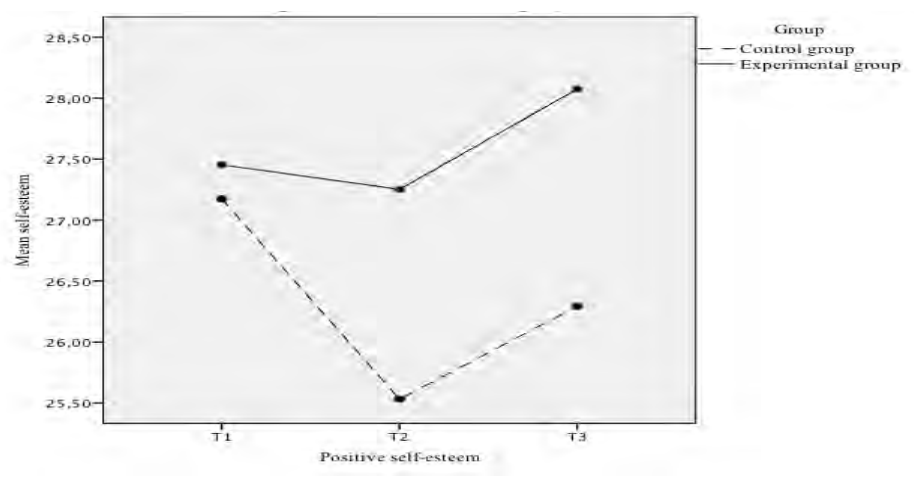


Figure 2. Diagram of the indirect effect of group on the satisfaction with themselves and surroundings through positive self-esteem among girls.

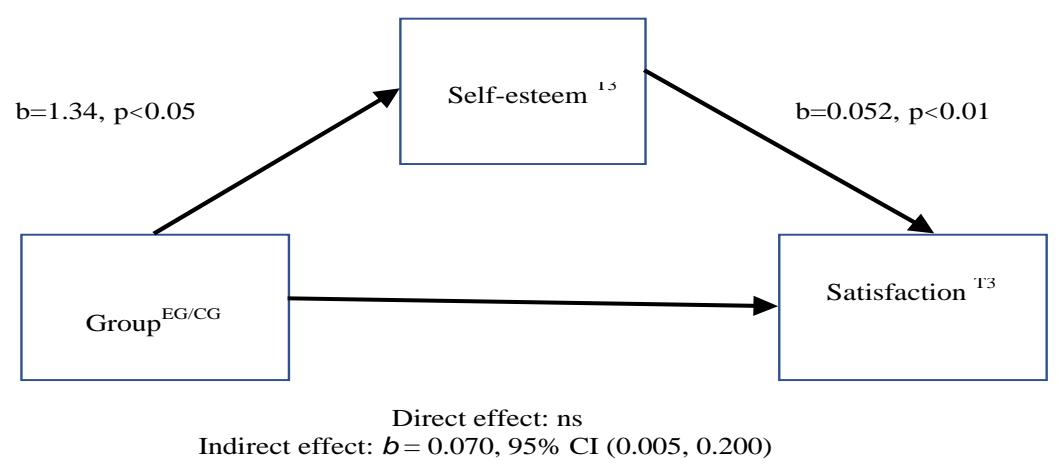

\section{Discussion and conclusions}

The results of this study have confirmed the partial indirect effect of the Unplugged program on satisfaction with themselves and surroundings through positive self-esteem that was found at the second follow-up test (three months after the Unplugged program implementation) only among girls. In line with these findings, a previous study confirmed the effectiveness of the Unplugged program through the development of a positive relationship with the teacher, empathy, decrease of conflicts, increased self-awareness and self-esteem and better school results (Carpi et al., 2015). The results of this study are also consistent with the statement that the Unplugged program, as a comprehensive social influence school curricula against substance misuse, may perform differently among girls and boys due to developmental and personality factors (Vigna-Taglianti, et al., 2009). Similarly, the effect of group-based, low-dose intervention on improving self-esteem was also found among girls from diverse cultural backgrounds (Tirlea et al., 2016). The mediation role of self-esteem between the Unplugged program participation and lifetime prevalence of cigarette smoking, a short-term indirect mediation effect of positive self-esteem in the program Unplugged, has also been confirmed by our previous analyses (Berinšterová et al., 2015).

On the other hand, while it was found that the Unplugged program was effective in reducing smoking, episodes of drunkenness and the use of cannabis in the short term, this association was confined to boys, with age and self-esteem as possible explanations of this difference (Vigna-Taglianti, et al., 2014).

This study found a significant main effect of time measures on the self-esteem expressed by schoolchildren and the levels of self-esteem differed between the participants and non-participants of the Unplugged program. The results confirmed the effectiveness of the Unplugged program via positive self-esteem three months after program implementation. However, the main effect of time measures on self-esteem did not differ between boys and girls. The results of this study supported a gender specific indirect effect of the program although a direct effect of the program for both genders.

In conclusion, the Unplugged program evaluation suggests that a comprehensive social-influence approach in the school setting could be effective in the direct and indirect improvement of personal skills and supports the need for a gender specific program effect evaluation. The level of psychological education of teachers responsible for the Unplugged program implementation, which is strongly based on interactive group work and quality of program implementation, will be able to deliver the program effect. The future of the Unplugged program implementation, as well as examining program effectiveness should reflect ,a need to adapt substance-use prevention programs to gender, peer gender, and the gender balance of schools..." (Grard, Kunst, Kuipers et all., 2018, p. 8).

\section{Acknowledgements}

This work was supported by Research and Development support Agency under the contract No. APVV-0253-11 and APVV-15-0662. 


\section{References}

Barker, E. T., \& Bornstein, M. H. (2010). Global self-esteem, appearance satisfaction, and self-reported dieting in early adolescence. The journal of early adolescence, 30(2), 205-224.

Berinsterova, M. (2015). The effectiveness of the school program of universal prevention "Unplugged". Dissertation thesis. Kosice: Pavol Jozef Šafárik University in Košice.

Berinšterová, M., Orosová, O., \& Miovský, M. (2015). Short term effectiveness of the Unplugged program in Slovakia: the Mediational role of self-esteem. European Journal of Public Health, 25(suppl_3).

Blood, G. W., Blood, I. M., Tramontana, G. M., Sylvia, A. J., Boyle, M. P., \& Motzko, G. R. (2011). Self-reported experience of bullying of students who stutter: Relations with life satisfaction, life orientation, and self-esteem. Perceptual and motor skills, 113(2), 353-364.

Carpi, A., Ferrari, M. B., Poggi, L., Chiesa, S., Costa, A., De, A. L., Rebolini, G., \& Gabutti, G. (2015). Health promotion in Local Health Unit 4 Chiavarese--Liguria Region, Italy." Unplugged" project: needs, methodology and implementation. Minerva pediatrica, 67(6), 495-503.

Duchesne, A. P., Dion, J., Lalande, D., Bégin, C., Émond, C., Lalande, G., \& McDuff, P. (2017). Body dissatisfaction and psychological distress in adolescents: Is self-esteem a mediator? Journal of health psychology, 22(12), 1563-1569.

Fernandes, H. M. (2018). Physical Activity and Mental Health in Adolescents: The mediating effect of Self-Esteem and Body Satisfaction. Revista de psicologia del deporte, 27(1), 67-75.

Fulginiti, A., \& Brekke, J. S. (2015). Escape from discrepancy: Self-esteem and quality of life as predictors of current suicidal ideation among individuals with schizophrenia. Community mental health journal, 51(6), 654-662.

Grard, A., Kunst, A., Kuipers, M., Richter, M., Rimpela, A., Federico, B., \& Lorant, V. (2018). Same-sex friendship, school gender composition, and substance use: a social network study of 50 European schools. Substance use \& misuse, 53(6), 998-1007.

Hibell, B., Guttormsson, U., Ahlström, S., Balakireva, O., Bjarnason, T., Kokkevi, A., \& Kraus, L. (2012). The 2011 ESPAD report: substance use among students in 36 European countries. Swedish Council for Information on Alcohol and Other Drugs. Stockholm. European Monitoring Centre for Drugs and Drug Addiction. Council of Europe. Cooperation Group to Combat Drug Abuse and Illicit Trafficking in Drugs (Pompidou Group).

Jozefiak, T., Kayed, N. S., Ranøyen, I., Greger, H. K., Wallander, J. L., \& Wichstrøm, L. (2017). Quality of life among adolescents living in residential youth care: do domain-specific self-esteem and psychopathology contribute? Quality of Life Research, 26(10), 2619-2631.

Låftman, S., \& Modin, B. (2017). Peer victimization among classmates-Associations with students' internalizing problems, self-esteem, and life satisfaction. International journal of environmental research and public health, 14(10), 1218.

Mei, S., Yau, Y. H., Chai, J., Guo, J., \& Potenza, M. N. (2016). Problematic Internet use, well-being, self-esteem and self-control: Data from a high-school survey in China. Addictive behaviors, 61, 74-79.

Tafarodi, R. W., \& Swann Jr, W. B. (2001). Two-dimensional self-esteem: Theory and measurement. Personality and individual Differences, 31(5), 653-673.

Tirlea, L., Truby, H., \& Haines, T. P. (2016). Pragmatic, randomized controlled trials of the Girls on the Go! Program to improve self-esteem in girls. American journal of health promotion, 30(4), 231-241.

Vigna-Taglianti, F. D., Galanti, M. R., Burkhart, G., Caria, M. P., Vadrucci, S., \& Faggiano, F. (2014). "Unplugged," a European school-based program for substance use prevention among adolescents: Overview of results from the EU-Dap trial. New directions for youth development, 2014(141), 67-82.

Vigna-Taglianti, F., Vadrucci, S., Faggiano, F., Burkhart, G., Siliquini, R., Galanti, M. R., \& EU-Dap Study Group. (2009). Is universal prevention against youths' substance misuse really universal? Gender-specific effects in the EU-Dap school-based prevention trial. Journal of Epidemiology \& Community Health, 63(9), 722-728.

Warren, F. (2016). 'What Works' in Drug Education and Prevention? 7 December 2016. [Social Research series] 